\title{
Sensationalism in argumentation: A case of the Zimbabwean parliament debates
}

\author{
Ernest Jakaza \\ Department of English and Communication, Midlands State University, Zimbabwe \\ E-mail: jakazaet@gmail.com
}

\begin{abstract}
Parliamentary debates are an argumentative interaction in which Members of Parliament (MPs) employ varied language devices in order to win debates in their favour. However, in an effort to win the debate at all costs, some parliamentarians seem to sensationalise their arguments in order to win favour or support from both internal and external audiences - the rationale judge. Sensationalism in argumentation is a presentation of an argument in a specific way in order to appeal to the hearer or the other participant's emotions or feelings. This article examines the role of sensationalism in argumentation, drawing its examples from the Zimbabwean parliamentary debates. The study is qualitative in nature, utilising a case study research design. It is couched in the Extended Pragma-Dialectic Theory of Argumentation. Debates from the Zimbabwean parliament are purposively sampled and the analysis is based on the argumentation theoretical framework. The article concludes that the main function of sensationalist language in parliamentary argumentation is rhetorical rather than dialectic. Arguers utilise sensationalist language to convince and win the debate in their favour. The use of sensationalism as an argumentative move is misused or abused, as it is a fallacious move.
\end{abstract}

Keywords: Sensationalism; emotion; argumentation; parliamentary discourse; Zimbabwe.

\section{Introduction}

This article discusses the notion of argumentation in parliamentary discourse. It is devoted to the examination of sensationalism in argumentation in the context of the parliamentary debates. With the increasing paradigm shifts and political polarisations in the Zimbabwean political landscape, it is important to examine the language and discourse that express the political agendas, the argumentation strategies, the deeper motivations and the ultimate goals of actors on the political stage in general, and in parliamentary institutions in particular (Ilie 2010). Discourse-linguistic strategies realised in the debates and speeches impact on the laws, general order of business of government and on people's real lives. According to Bayley (2004), parliaments are dedicated to talks with Members of Parliament (MPs) debating legislative proposals and scrutinising the work of government through adversarial questioning.This article argues that in efforts to win the debate at all costs, parliamentarians 
seem to sensationalise their arguments in order to win favour or support from both internal and external audiences.

This article is divided into six sections. In the first section, I characterise the discourse and the institutional context of parliament where the act of sensationalism in argumentation is realised. In section 3 I discuss the aspects of argumentation in discourse. I also argue for the use of the Extended Pragma-Dialectic Theory of Argumentation in the same section. Section 4 is devoted to the discussion of the notion of sensationalism in argumentative discourse. I indicate that the study of sensationalism in language use is on the increase as evidenced by a number of studies in various contexts. In section 5, I make clear the corpora and methods used in the study. Lastly, I examine sensationalist language in argumentation as realised in the Zimbabwean parliament in section 6. I argue for the presents of sensational argumentative patterns realised in the discourse of parliamentarians. Among the patterns identified and discussed are Spiritual/ cultural sensations, Metaphorical sensations, Evidentiality sensations and Gender sensations. The display of sensations is argued to "vary from blatant to subtle to unspoken, or anything in between" (Du Bois and Kärkkäinen 2012: 434). I conclude the article citing the findings of the research and suggesting areas for further study.

\section{Parliamentary discourse as the context}

The notion of sensationalism is explored in the context of the parliamentary debates. In parliament, it is parliamentary discourse or talk that is exhibited. Parliamentary discourse has been unduly constituted as a sub-genre of political discourse, which is typically formal, and predominantly argumentative (van Dijk 2002; Fairclough and Fairclough 2012).Parliamentary debates are "the original centres of political processes" (Holly 2008: 317). Although it has been argued to belong to political discourse, parliamentary discourse has distinct ways of using language that differentiates it from the other political acts. The institution of parliament dictates how parliamentarians are supposed to behave during debates and speeches. The code of conduct stipulates "rules regarding forms of address, turn-taking, form/type of language to be used et cetera are evident" (Jakaza 2013: 27). The institutional burden of proof imposes preconditions on how one is expected to participate in the argumentative activity type (Snoeck-Henkemans and Mohammed 2012). The rules and regulations pertaining to language use in parliament provide the ideal situation for the display of sensationalism in discourse. However, the ideal and what transpires during debates in the parliament do not always match. An asymmetrical relationship between the ideal and the actual is perpetuated by sensationalism in argumentation. According to Archakis and Tsakona (2009: 362), parliamentary debates and speeches are characterised by rhetoric in which members of parliament "resort not only to legal and political argumentation, but to informal and emotional registers."

As a rule-regulated interaction, parliamentary exchanges are controlled by the Speaker/Deputy Speaker or President/Deputy President. Parliamentarians are not only expected to advance facts but to speak when given the opportunity to do so by the Speaker/Deputy or President/Deputy President who act as judges of rationale. Parliamentary discourse is argumentative in nature. What might differ is the level of the difference of opinion. Being argumentative and regulated, parliamentary interactions are impacted by interjections full of emotions and affect. The competitive environment of parliament calls 
MPs to always be on the lookout for a criticism from both the internal and external audience. Ilie (2003a) argues that in parliament three types of audience occur - the insider audience of fellow Members of Parliament, the outsider audience of visitors in the strangers' gallery and the outsider audience of television viewers. However, for MPs, Ilie (2006) argues that, although they recognise the outside audience, their targeted audience is the insider audience, thus fellow MPs. Ilie (ibid) further observes that the main reason for MPs to target fellow MPs in argumentation is that the outsider audience "is normally a random and continuously changing audience" (Ilie 2006: 194). The argumentation theory being utilised in this article aptly states that speakers strategically manoeuvre in argumentation adjusting to audience demand (van Eemeren and Houtlosser 2002). The study argues that sensationalism in argumentation is a form of strategic manoeuvering realised explicitly or implicitly in parliamentarians' discourse engaged for the purposes of winning a debate in one's favour. However, it should be noted that sensationalising arguments may overshadow reasonableness and result in fallaciousness in argumentation.

\section{Argumentation}

The concept of argumentation in this article is informed by the Extended Pragma-Dialectic Theory as envisaged by van Eemeren and Houtlosser $(2002,2009)$ and van Eemeren (2010, 2017). The tradition on the study of argumentation can be traced back to "classical dialectics in concentrating on critical scrutiny of standpoints" (van Rees 2000: 256) and ancient Greek writings on logic (proof), rhetoric (persuasion), and dialectic (inquiry) (van Eemeren and Garssen 2015). Taking a pragma-dialectic approach, argumentation is defined as "a social, intellectual, verbal activity serving to justify or refute an opinion, consisting of a constellation of statements and directed towards obtaining the approbation of an audience" (van Eemeren, Grootendorst, and Kruger 1987: 7). In the same vein, it is understood as a "communicative and interactive (speech) act complex aimed at resolving a difference of opinion before a reasonable judge by advancing a constellation of reasons the arguer can be held accountable for as justifying the acceptability of the standpoint(s) at issue" (van Eemeren 2010: 29).Van Eemerenand Garssen(2015) go further to state that language is the core of argumentation as it is used to justify or refute a standpoint with the sole purpose of securing agreement between or among the parties involved. Parliamentarians engage in argument-based debates using language to convince others of the truth or acceptability of what they persent. Policies and laws or acts of parliament are passed when a consensus is reached.

Argumentation is a guided process. It is guided by the critical discussion model. This model has been formulated with the aim of resolving a difference of opinion on the merits (van Eemeren and Grootendorst 1984; van Eemeren and Houtlosser 2002). The model is influenced considerably by the dialectical notion of reasonableness. The notion of reasonableness entails that nothing is a certainty, hence every claim is supposed to be subjected to a critical test. In critically testing the standpoints, the critical discussion model then specifies the dialectical stages that have to be distinguished in resolving a difference of opinion as well as the moves that serve a constructive purpose in the different stages of the resolution process (van Eemeren and Houtlosser 2002; van Eemeren 2010). There are rules governing the conduct of the parties in this critical discussion. These rules state the norms that are supposed to be followed in all the stages in the resolution of the difference of opinion. The parties involved in the argumentative discussion are bound by these rules. Deviation from the 
norm set by the rules in the argumentative process is taken as a 'discussion move that obstructs or hinders the resolution of the difference of opinion on the merits' (van Eemeren 2010: 7). This move is regarded as fallacious as it violates the 'code of contact', which are the rules set within the pragma-dialectic theoretical model of a critical discussion. Sensationalism in argumentation is argued to be an argumentative move, a rhetorical process meant to convince the other participants ofthe truth or acceptability of a standpoint or position. Thus, sensationalism is a rhetorical move and not dialectic.

At the core of the argumentation theory are two competing terms; rhetoric and dialectic. The antagonism between the two harkens back to the classical period. However, since then scholars have seen no reason to separate them. The notion of strategic manoeuvering was introduced in the integration of rhetoric and dialectic ${ }^{1}$ (van Eemeren and Houtlosser 2002, 2009). According to van Eemeren and Houtlosser (2009), strategic manoeuvering refers to the continual efforts made in principle by all parties in argumentative discourse to reconcile the simultaneous pursuit of rhetorical aims of effectiveness and dialectical standards of reasonableness. Thus, strategic manoeuvering is a way of trying to manage the 'argumentative predicament' which arises when trying to balance effectiveness with reasonableness (van Eemeren 2017). In other words, the notion has been developed to take into account the fact that "engaging in argumentative discourse always means being at the same time out for critical reasonableness and artful effectiveness" (van Eemeren and Houtlosser 2002: 4). This view is based on the fact that arguers do not only want their words to be understood but also accepted and dealt with accordingly. In argumentation arguers have to balance reasonableness and effectiveness. Thus, in order to resolve the difference of opinion on merits, parliamentarians are required by the critical discussion rules and normative standards of argumentation to defend their standpoints through dialectical reasoning. This article discusses the role of emotions, feelings or affect in argumentation in the context of parliament.

\section{Sensationalism in argumentation}

The focus of the article is on sensationalism in argumentative discourse. Sensationalism in argumentation is a presentation of an argument in such a way that it appeals to the hearer or the other participant's emotions or feelings. Often, sensationalism is seen as a breach of standard argumentative practices (van Eemeren 2017). Bringing in emotions or affect into one's argument derails the strategic manoeuvering efforts to balance reasonableness and effectiveness in argumentation. Parliamentarians find themselves in an 'argumentative predicament' as they are expected to present logical arguments effectively. However, considering that human beings are emotive in nature it is difficult to remove sensations from one's argument, and in fact emotion is commonly present in interaction, either implicitly or explicitly (Du Bois and Kärkkäinen 2012). It is important to understand the function or purpose of these emotions in discoursive practice. Van Eemeren and Garssen (2015) posit that dialectical and rhetorical perspectives on argumentative discourse are not only complementary but also compatible. Sensationalism in argumentation should be seen as a rhetorical strategy and linguistic device engaged in order to effectively resolve the difference of opinion in one's favour.

${ }^{1}$ For a detailed discussion on strategic manoeuvring, refer to van Eemeren and Houtlosser (2002), van Eemeren (2010), and Jakaza (2013). 
Van Eemeren and Houtlosser (2002) note that maintaining a balance between reasonableness and effectiveness should always go together in every argumentative move being made. Even though the topic that has been tabled might arouse emotions, or the arguments advanced are provocative, the arguers are supposed to contain their affect. However, this is an idealized outcome as in reality, parliamentary discussions are often dictated and directed by emotional affect. Apart from verbal emotionally charged arguments, cases of fist fighting have been recorded in parliament as well which resulted from such emotional argumentation. Thus, this article focuses on sensationalism in argumentation in the context of the Zimbabwean parliament. Sensationalistic language exhibited in parliamentarians' argumentative practices will be discussed and an evaluation of how the use of such a 'strategy' contributes to resolving the difference of opinion with merits will be made.

\section{The corpora and method}

The article is on sensationalism in argumentation drawing its corpora from the Zimbabwean parliamentary debates. It is qualitative in nature utilising a discourse-analytic case study design. Debates from 2009-2010 have been purposively sampled and considered with regards to the speakers' ranks (such as minister, President) and whether the debate or speech was of national interest, emotional, or of public interest, as well as the number of speakers or contributors to the topic being deliberated (Elspa $\beta$ 2002). The period (2009 to 2010) was chosen deliberately because it captures 'historic' parliament in Zimbabwe- when the Government of National Unity (GNU) formed after the disputed elections of 2008 which put to an end the twenty-eight year period of ZANU-PF political dominance ${ }^{2}$. This pragmatic context calls for parliamentarians to resort to strategic moves in parliament in order to win debates marketing themselves and their political parties. On top of that, Zimbabwe was coming from a highly contested election where rampant acts of violence were recorded. Discussions in parliament are largely informed by what is happening in the greater societal context. Thus, it is highly unthinkable to talk of non-emotional debates in parliament during this period. The article explores the function language serves in the construction of sensationalist arguments realised in Zimbabwean parliament during this period. Various functions of sensationalist language in argumentation are examined as informed by the Extended Pragma-Dialectic Theory of Argumentation.

\section{Sensationalist language in argumentation}

This section focuses on the analysis of parliamentary debates from Zimbabwean parliament with the interest to identify and examine instances of sensationalist language realised in argumentation. Overt (obvious) and covert (subtle) instances of sensationalism are distinguished first. Overt sensationalism is defined as an instance in which language (words, phrases or clauses) that evokes feelings, emotions or affect can be noted in text. On the other hand, covert sensationalism is realised even if there is no explicit language that can be attributed to the emotions or feelings being evoked. Subtle sensationalism might also be

\footnotetext{
${ }^{2}$ Some of the data used in this article was used in a Doctoral dissertation on Argumentation and Appraisal in Zimbabwean Parliamentary debates by Jakaza (2013). However, the analytical perspective and dimensions are original.
} 
realised through references made to documents, persons, pictures or videos as additional information pertaining to the debate.

A thematic approach informed by the Extended Pragma-Dialectic Theory of Argumentation is utilised to structure and analyse sensationalist language. Examples of data where sensationalist language is realised is presented, followed by a discussion on the reasons and effects of such forms of strategic manoeuvering during argumentation in parliament. It should be noted that multiple cases of sensationalism are realised, but only a few are considered to be sufficient for the understanding of sensationalist language in argumentation.

\subsection{Gender sensations}

For argumentation to ensue, there is necessarily a difference of opinion at hand. Participants engage in an argumentative discussion to erase any doubt concerning the propositions made. As van Eemeren (2010) notes, it is at the confrontation stage that all positions are explicitly challenged. Gender related issues are challenged in patriarchal societies, the presenter of the motion in parliament will always be expecting antagonism and gender semantics are biased towards females. Hence, when one brings gender topics to discussion they will divide the house along gender relations: that is, whether you are female or male. Unproven assumptions are that it is given knowledge that a gender imbalance is evident with women being at the receiving end, and only female parliamentarians advance the cause of equality for other females. In such situations, emotions or feelings are bound to be realised in the argumentation process. Presenting a debate on the ratification of the Southern Africa Development Community (SADC) protocol, the then Minister of Women's Affairs, Gender and Community Development, Dr. O. Muchena, female minister, as the protagonist, gave a report back on the position that was taken by the Southern African Development Community (SADC) heads on the protocol where Zimbabwe is a signatory. The attribution of who is the antagonist and who is the protagonist in an argumentative debate is largely implicit (van Eemeren 2017) because it is based on assumption that this is the initial stage of argumentation and that the first to advance the proposition is the protagonist and the second participant who raises any doubt on the first participant's proposition becomes the antagonist by default. The minister is implicitly assigned as the protagonist and advances her standpoints. The assumed antagonists are the senators and male chauvinists. In order to convince members of the senate, the minister argues an ad misericordian fallacy showing how important the protocol is to women's lives. Arguing from analogy and ad misericordian, she further points out that the rights in protocol are also found in other human rights instruments, namely the UN convention on the protocol to the African Charter on Human and People's Rights on the Rights of Women in Africa. Analogy and ad misericordian argumentative moves sensationalise the debate. Participants in the debate are persuaded to sympathise with the motion and the protagonist.

In sensationalising the motion advanced, Chief Charumbira, a leader of chiefs and aligned to Dr O. Muchena's ZANU PF ruling political party, a custodian of the Chishona culture and being male, did not only evade the burden of proof but confirms the negative feelings that might arise if parliamentarians do not ratify the gender protocol.

(1) We are always accused of being anti-women, unprogressive implementing and crafting some outdated practices in the name of culture but I want to say let us prove 
these people wrong... (Ratification of the SADC Protocol on Gender and Development debate, 21 October 2009)

Charumbira did not only argue from a fallacy of false cause and authority, but also from poisoning the well. Explicit and overt sensational language such as 'anti-women', 'unprogressive' and 'outdated' are utilised strategically to raise the cost of going against such an argument and aligns everyone, especially males, with the idea that the protocol has to be ratified. Sensationalist language presents the protocol as a challenge before anyone in the house, as an obligation laid at the feet of every senator to show the true picture of gender relations in Zimbabwe. The extent to which the debate was positively sensationalised encouraged other contributors more supportive. Sensationalist language utilised in the debate greatly contributed to ratification of the SADC Protocol on Gender and Development.

\subsection{Spiritual sensations}

A human being is not only a religious being but also a spiritual one. Spirituality cannot be easily divorced from one's feelings. Though the Zimbabwean Constitution of 2013 embraces freedom of worship and religion, Zimbabwe is largely a Christian country. During debates in parliament, references to the Christian Bible are evident. The Bible is not only an authority during argumentation but is also used to evoke spiritual sensations. The assumption that one cannot refute what is written in the God-ordained book is made, as it is argued that the Bible was written under God's spiritual guidance. In advancing his standpoint, Hon. Mazikana (ZANU PF MP) quotes the Bible in order to convince opponents that they are supposed to forgive and forget. Reference to the Bible is being made strategically considering the motion being discussed and the Zimbabwean context. The authority that the Bible has in a Christian community makes one retract their standpoint. However, the Bible can also be interpreted and used in 'unholy' circumstances. MDC Hon. Member, Mr Chitando also cites a long Bible verse used during the campaign for the June 272008 Presidential election rerun in an attempt to sanction violence:

(2) I would like to say to Hon. Mazikana who was quoting the Bible and I want to also quote the Bible and read the verse which was read by these people [ZANU PF militia]...It is in Ezekiel chapter 9 verses 6 and 7 which says "kill the old men, young men, young women, mothers and children but do not touch anyone who has the mark on his forehead. Start here at my temple. So they began with the leaders who were standing there at the temple." Verse 7 says "God said to them defile the temple. Fill its courtyards with corpses. Get to work! So they began to kill the people in the city". That was the verse that was being read at the base (Violence after $29^{\text {th }}$ March 2008 Elections, Vol. 36, No. 28, 17 ${ }^{\text {th }}$ March 2010).

(3) Our debate is focusing on "we are innocent", "they are guilty". John says "if we have not sinned then we are not truthful". (Violence after 29 ${ }^{\text {th }}$ March 2008 election, Vol. 36. No. 28, $17^{\text {th }}$ March 2010)

Dialectically, the counter argument in example 2 exposes Hon. Mazikana. The Bible cannot be used as a premise for making conclusions in order to resolve differences of opinion. Reference to the Bible is a fallacious move that might obstruct the resolution of the problem. Rhetorically, this counter reference to the Bible strategically reinforces the MDC's standpoint 
and aligns participants with the motion. Hon. Chitando evaluatively endorsed the Bible verse, explicitly positioning himself against use of the Bible to spiritually sensationalise arguments as it can be wrongly interpreted and misused, especially if employed out of context. Thus, even though spiritual sensations can be persuasive, they are not dialectical.

\subsection{Metaphorical sensations}

Metaphors are regular phenomena in political debates. Plug and Snoeck-Henkemans (2008: 102) argue that metaphors "make it possible to comprehend one kind of thing in terms of another and thereby enable a speaker to highlight or hide specific aspects of a concept." Jakaza (2013) also states that "metaphors are central in the production of linguistic meanings and so pervasive in language in general." Metaphors contribute to the persuasiveness of an argument. They are strategically utilised to associate the audience with a particular standpoint, thereby negatively evaluating the other participant, standpoint or political party.

(4) We are helping them to be repentant; we want a Damascus change- a change from Saul to Paul. ...we should take political violence as the evil it deserves... what were the root causes of this violence so that if we get collective action of what we should do to correct this anomaly, to correct this illness that is pervasive in our society... We know we have those who underwent a moment of madness... (Violence after $29^{\text {th }}$ March Election, Vol. 36. No. 27, $16^{\text {th }}$ of March 2010)

(5) Madam speaker, elections should notbe a matter of life and death; elections should not be like a war. Let us look at Botswana- we had a motion in this August House where the SADC observer mission commended the people of Botswana for peaceful elections. Not a single life was lost in Botswana. More so, the elections in Namibia, not a single soul lost life as a result of elections (Violence after $29^{\text {th }}$ March 2008 Elections, Vol. 36, No. 27, $16^{\text {th }}$ March 2010).

In example 4, Mudzurimakes use of different types of metaphors that complement each other.For metaphors to be persuasive, they have to be appropriate, clear and understood by the other participant. The Biblical/religious metaphor- Damascus change- that Mudzuri utilised has been explained to make sure that the audience has comprehended it. In further sensationalising his discourse, Mudzuri labels ZANU PF MPs and party as evil, ill, and under the influence of madness. There is a sharp division that is given. MDC and its MPs are positively sensationalised and ZANU PF and its MPs are negatively evaluated.

In employing association, the protagonist not only negatively evaluates the presumed violent group, but also dialogically contracted the argument space aligning the audience to the idea that an election where no lives are lost is best. The speaker establishes a link between the Zimbabwean elections and the two elections in Botswana and Namibia associating the audience with 'commended' elections, negatively sensationalising and judging the Zimbabwean elections. The protagonist poses the idea that if Botswana and Namibia are also countries in the SADC, Zimbabwe must emulate them. Through the use of explicit sensational forms such as 'a single life', 'not a single soul', the protagonist immunises the motion against criticism. Metaphorically, the Honourable member aligns the audience to his side by comparing an election to a war or viewing an election as a matter of life and death. Obviously, he knew that no one would want to be identified with a war-like election. The 
metaphor does not only show the gravity of the problem but also associates the audience with the motion of setting up a select committee to resolve the problem. Metaphors are important as they are utilised strategically to build one's argument and stylistically establish the picture of what is being talked about, thus persuading the audience to align and resolve the problem in their favour.

\subsection{Affect and emotive sensations}

Affect has been studied from various perspectives. However, the general consensus from these studies is that affect has to do with feelings, attitudes, moods and dispositions associated with persons and/or situations. According to White (2005: 4), affect is "concerned with emotions, with positive and negative emotional responses and dispositions." These emotions are expressed directly (explicit or inscribed) or indirectly (implicit or invoked). Research into emotions/affect has shown that "emotions are complex physiological-affective-cognitive responses to the physical and social/cultural environment" (Bednarek 2008: 148) that cannot be easily classified. This article is not focusing on the classification of affect/emotions, but rather discusses the role of affect in argumentation.

(6) It is saddening to note that even most of the cases which gets to our courts some of them will not receive a fair adjudication they deserve. (Condemnation of corrupt practices, Vol. 36 No. $8.10^{\text {th }}$ November 2009)

(7) This report clearly shows that he had fractured legs and ribs and swollen genitals due to assault. (Violence after 29 ${ }^{\text {th }}$ March 2008 Election, Vol. 36. No. 28, 17 ${ }^{\text {th }}$ March 2010).

Through the explicit affect behavioural surge value of 'saddening' in example 6, the protagonist and mover of the motion appeals to emotion in order to exploit emotional triggers in listeners. Emotions show the degree to which the speaker is involved or has been affected by something. Thus, appeal to emotion has been strategically utilised to align the listeners with the protagonist's line of thinking. In example 7, the arguer implicitly evokes the audience's emotions by making reference to fractured legs, ribs and swollen genitals. The rationale judge is sensationalised and emotionally charged to the reasoning that the acts of violence perpetrated by ZANU PF on MDC are not only bad, but also uncalled for. The argument is presented dialectically noting the facts at hand and at the same time rhetorically persuading the antagonist to see the 'bad' acts committed. As Martin and White (2005: 215) observe, "texts such as these are as much about personal recollection, observation and storytelling as they are about explicit development of an argumentative position." The use of emotive language or humanistic rhetoric in argumentation is one of the aspects that have been argued to be a hindrance to standard argumentative practices. Instead of rationally resolving the problem at hand, the rationale judge is emotionalised and persuaded to pass an effectual judgement.

\subsection{Cultural sensations}

Among other strategies that parliamentarians utilise to sensationalise their arguments is reference to culture, and particularly political culture. Lauerbach and Fetzer (2007: 8) argue that in terms of political discourse analysis "culture is the premise that members of a speech 
community know about their community's appropriate ways of producing and interpreting explicit and implicit meaning." Bayley (2004: 5) also states that "Political culture is determined by long-term orientation to government and general beliefs, symbols and values". Through culture, members of a speech community are able to interpret explicit and implicit meanings informed by the knowledge systems and discourse practices that they share. Culture is strategically employed to sensationalise their arguments and silence discordant voices, encouraging the acceptance of the status quo. ZANU PF parliamentarians positively evaluated Masawi arguing from the Shona cultural perspective; 'wafawanaka' (If one dies they become good). This view is highlighted by one ZANU PF MP who states that:

(8) "In our African culture we are not supposed to say anything bad about a dead person..." (Condolences on the death of Senator Patrick Kombayi, Vol. 37 No. 13, 28 ${ }^{\text {th }}$ July 2009)

In example 8, ZANU PF MPs sensationalise their argument by making reference to culture in an effort to pacify MDC MPs and make them accept their position. However, exploiting the weakness in the proverb as a premise for calling upon all members of parliament to only positively appraise Masawi, Madzimure gave a counter Shona proverb "zvinonziukaonapachiitwazvakadaropanguvayakadaro, pane azunzachidembo" (Literally: It is said if you see such things happeningat such a time it means that there is something wrongsomeone shook the civet cat) (Condolences on the death of Cde Ephraim Sango Masawi, Vol. 37 No. 13, 16 November 2010). Thus, Madzimure sources an undisclosed authority from culture and figuratively advances his argument. Cultural sensations can be easily manipulated by arguers for selfish gains. The moment cultural sensations are realised in argumentation to serve that purpose, they derail the argumentation process. In standard argumentation practices (van Eemeren 2017), participants in an argumentative activity should balance reasoning and effectiveness. The argument raised in example 8 is a cultural fact, which is defective in the context of parliament.

\section{Conclusion and Recommendations}

The present article discussed sensationalism in argumentation as it is realised in Zimbabwean parliamentary debates. The discussion was couched in the Extended Pragma-Dialectic Theory of Argumentation. The analysis of sensational language was guided by the standard argumentative practices enshrined in the Critical Discussion Model. Sensationalism in argumentation has been taken as a strategic manoeuvre that both the protagonist and antagonist may use, and is aimed at resolving a difference of opinion with merits. The analysis of parliamentary debates has shown that sensational language is abundant in argumentative discourse. Sensationalism in argumentative discourse has been argued to be realised in various forms during argumentation. However, the main function of sensationalism is persuasion and winning the debate in one's favour. Sensationalism is a rhetorical tool that arguers utilise to convince others to accept their stand-point. The use of sensational language seems to be misused or abused by parliamentarians. Instead of balancing reasoning and effectiveness, parliamentarians seem to aim to be effective when utilising sensational language. Examples given above have shown a number of cases in which sensational manoeuvering was noted as a means of derailing the difference of opinion with merits. Thus, sensationalism is largely realised as a fallacious move. The article concludes that a delicate 
balance in the use of sensational language should be realised for an amicable resolution of the difference of opinion to be reached as sensationalism impacts on argumentation, policies and acts of parliament that are passed. Decisions reached and implemented in parliament impacts citizens' lives. If these decisions are made on a sensational basis and not dialectical reasoning, unbalanced laws and policies might be crafted and passed.

I recommend that sensationalist language be strategically utilised in order to effectively win the debate and resolve the problem amicably. Debates in parliament should appeal to reason more than to emotion. Rhetoric has to be balanced with dialectics. Emotive and affective decisions negatively impact on a country's policies. However, further research has to be carried out on the extent to which sensationalist argumentation affects and impacts decisions reached in the parliament.

\section{References}

Archakis, A. and V. Tsakona. 2009. Parliamentary discourse in newspaper articles: Theintegration of a critical approach to media discourse into a literacy-based language teachingprogramme. Journal of Language and Politics 8(3): 359-385. https://doi.org/ $\underline{10.1075 / \mathrm{jlp} .8 .3 .02 \mathrm{arc}}$

Bayley, P. 2004. Introduction. The whys and wherefores of analysing parliamentary Discourse. In P. Bayley (ed.) Cross-cultural Perspectives on Parliamentary Discourse. Amsterdam: John Benjamins Publishing Company. pp. 1-44. https://doi.org/ 10.1075/dapsac.10.01bay

Bednarek, M. 2008. An increasingly familiar tragedy: Evaluative collocation and conflation. Functions of Language 15(1): 7-34. https://doi.org/10.1075/fol.15.1.03bed

Du Bois, J.W. and E. Kärkkäinen. 2012. Taking a stance on emotion: affect, sequence, and intersubjectivity in dialogic interaction. Text and Talk 32(4): 433-451. https://doi.org/ $\underline{10.1515 / \text { text-2012-0021 }}$

Elspaß, S. 2002. Phraseological units in parliamentary discourse. In P. Chilton and C. Schäffner (eds.) Politics as Text and Talk: Analytic Approaches to Political Discourse. Amsterdam: John Benjamins. pp. 81-110. https://doi.org/10.1075/dapsac.4.06els

Fairclough, I. and N. Fairclough. 2012. Political Discourse Analysis: A Method for Advanced Students. London and New York: Routledge.

Holly, W. 2008. Tabloidization of political communication in the public sphere. In R. Wodakand and V. Koller (eds.) Handbook of Communication in the Public Sphere. Berlin: Walter de Gruyter. pp. 318-341. https://doi.org/10.1515/9783110198980.3.317

Ilie, C. 2003. Discourse and Metadiscourse in parliamentary debates. Journal of Language and Politics 1(2): 269-291.

Ilie, C. 2006. Parliamentary discourses. In K. Brown (ed.) Encyclopaedia of Language and 
Linguistics (2 ${ }^{\text {nd }}$ edition). Oxford: Elsevier. pp. 188-196.

Ilie, C. 2010. Introduction: Analytical perspectives on parliamentary and extra-parliamentary discourses. Journal of Pragmatics 42: 879-884. https://doi.org/10.1016/j.pragma.2009.09.015

Jakaza, E. 2013. Appraisal and Evaluation in Zimbabwe Parliamentary Discourse and its Representation in Newspaper Articles. PhD dissertation, Stellenbosch University.

Lauerbach, G.E. and A. Fetzer. 2007. Political Discourse in the Media: Cross-cultural Perspectives. Philadelphia: John Benjamins.

Martin, J.R. and P.R.R. White. 2005. The Language of Evaluation: Appraisal in English. London: Palgrave Macmillan.

Plug, J. and F. Snoeck-Henkemans. 2008. Apologies for metaphors as a strategic manoeuvre inpolitical debates. In L. Dam, L-L. Holmgreen and J. Strunck (eds.) Rhetorical Aspects of Discourses in Present Day Society. Newcastle: Cambridge Scholars Publishing. pp. 102-116.

Snoeck-Henkemans, A.F. and D. Mohammed. 2012. Institutional constraints on strategic manoeuvering in shared medical decision-making. Journal of Argumentation in Context 1(1): 19-32. https://doi.org/10.1075/bct.64.03moh

Van Dijk, T.A. 2002. Political discourse and political cognition. In P. Chilton and C. Schäffner (eds.) Politics as Text and Talk: Analytic Approaches to Political Discourse. Amsterdam: John Benjamins. pp. 203-238. https://doi.org/10.1075/dapsac.4.11dij

Van Eemeren, F.H. 2010. Strategic Manoeuvring in Argumentative Discourse. Amsterdam: John Benjamins.

Van Eemeren, F.H. 2017. Argumentative patterns viewed from a pragma-dialectical perspective. In F.H. van Eemeren (ed.) Prototypical Argumentative Patterns: Exploring the Relationship between Argumentative Discourse and Institutional Context. Amsterdam: John Benjamins. pp. 7-30. https://doi.org/10.1075/aic.11.02van

Van Eemeren, F.H. and B. Garssen. 2015. Analysis and evaluation of argumentative discourse. In F.H. van Eemeren (ed.) Reasonableness and Effectiveness in Argumentative Discourse: Fifty Contributions to the Development of Pragma-dialectics. Amsterdam: Springer. pp. 507-519. https://doi.org/10.1007/978-3-319-20955-5_26

Van Eemeren, F.H., R. Grootendorst and T. Kruger. 1987. Handbook of Argumentation Theory: A Critical Survey of Classical Backgrounds and Modern Studies. Dordrecht: Foris Publications. https://doi.org/10.1515/9783110846096

Van Eemeren, F.H. and P. Houtlosser. 2002. Strategic manoeuvering: Maintaining a delicate balance. In F.H. van Eemeren and P. Houtlosser (eds.) Dialectic and Rhetoric: The Warpand Woof of Argumentation Analysis. Dordrecht: Kluwer. pp. 131-159. https://doi.org/10.1007/ 978-94-015-9948-1_10 
Van Eemeren, F.H. and P. Houtlosser. 2009. Strategic manoeuvering: Examining argumentation in context. In F.H. van Eemeren (ed.) Examining Argumentation in Context: Fifteen Studies on Strategic Manoeuvering. Amsterdam: John Benjamins. pp. 1-24. https://doi.org/10.1075/aic.1.02eem

Van Rees, M.A. 2000. Comments on rhetoric and dialectic in the twenty-first century. Argumentation 14(3): 255-259. 